\title{
COVID-2019: Digital Norm-Making
}

\author{
Khaydarali Mukhamedov ${ }^{1}$, Azizjon Khujanazarov ${ }^{2}$ \\ ${ }^{1}$ Professor, ${ }^{2}$ Lecturer, Department of Theory of the State and Law, Tashkent State University of Law, 35 Sayilgoh, \\ Tashkent, 100047, Uzbekistan
}

\begin{abstract}
This article analyzes digital norm-setting activities, the introduction of digital technologies into normsetting, norm-setting platforms, norm-setting modernization issues, and digitalization during a pandemic to prevent the spread of viruses along with health care for both the legislature and the local population. The article examines the scientific works of legal scholars in the field of norm-setting and, based on these sources, covers the topic and outlines several problems in the field of digital norm-setting in a pandemic. The article develops the author's proposals on the development, discussion, examination, and legal examination of normative legal documents using information technology, facilitation of their adoption and delivery to the public, and health. Based on these recommendations, the author argues that the Pandemic should prevent COVID-19 and other emergencies in the protection of the health and time of professionals working in law enforcement agencies.
\end{abstract}

Keywords: Digital norms, norm-making, technology, acts, health, coronavirus pandemic, COVID-19.

\section{Introduction}

The COVID-19 pandemic is the current global pandemic of the COVID-19 coronavirus infection caused by the SARS-CoV-2 coronavirus. The outbreak was first reported in Wuhan, China in December 2019. The outbreak was declared a public health emergency of international concern by the World Health Organization on January 30, 2020, and a pandemic on March 11. As of December 9, 2020, the pandemic had more than 69.1 million cases worldwide; more than 1.573 million people died and more than 47.8 million recovered ${ }^{1}$.

According to health organizations, a person infected with the coronavirus can be infected by any object or object that is likely to contain a hand, door handles, money, table-chair surfaces, paper, windows, stairs, bars, and other viruses.

A take, given that COVID-2019 is transmitted through documents and other things, the use of digital technologies during a pandemic, i.e. working with electronic materials, is beneficial to humans.

The global trend is that digital technologies are somewhat advanced in all developed countries. Indeed, the development of a society in which globalization has changed (transformed, updated) and introduced the latest technologies in the process of integration with the world community is important.

To achieve development, we must first acquire digital knowledge and modern information technology. Digital technology increases public and public administration, productivity in the social sphere, improve people's lifestyles.

At the same time, the modernization of normative creativity, in particular digitalization, also prevents the spread of viruses, mainly in conjunction with health care, not only for the legislature but also for the population during a pandemic.

Indeed, the development, discussion, expertise and legal expertise of normative and legal documents using information technology, as well as facilitating their adoption and dissemination to the public, is also important in health care.

\section{Material and Methods}

In the field of norm-making based on the following 
methods:

1. The Concrete-sociological method often turns out to be the only correct one when studying various spheres of activity of legal and state institutions, when it is necessary to assess the effectiveness of decisions made, the timeliness and effectiveness of legal regulation or legal protection.

2. The Comparative legal method is no less important in the methodology of state and legal studies than the specific sociological method. The comparative method involves comparing concepts, phenomena and processes and finding out the similarities and differences between them. As a result of the comparison, the qualitative state of the legal system, the state structure as a whole, or individual, for example, legal institutions and norms are established.

However, it is important to take into account one condition: the objects to be compared must be comparable. Let's explain with examples. You can compare legal systems, state structures, and similar legal institutions and norms. But you cannot compare, for example, the legal system in General and individual legal norm of These objects is incomparable for the level, scope, contents and grounds.

3. Specifics and main functions of the legal method. Formal-legal (normative-dogmatic) can be rightly called traditional, characteristic of legal science, resulting from its nature. Its essence is that the law is studied as such: it is not compared to anything, it is not linked to the economy, politics, morality, or other social phenomena ${ }^{2}$.

\section{Findings}

During this article, the scientific works and research works of legal scholars in the field of norm-setting were studied. The relevance of the topic was highlighted based on the collected sources on norm creation, and several problems in the field of digital norm creation in the context of a pandemic were highlighted in the article.

Lawyer scientist M.K.Najimov described the concept of legal expertise as the activity of legal entities and individuals to conclude the point of view of their compliance with the accepted legal document or its draft constitution and legislation, as well as the established rules of legal technology ${ }^{3}$.

The legal expert of the draft law is to assess the compliance of the draft law with the RF Constitution and its position in the system of current legislation and international treaties, as well as to check its quality and effectiveness of the rules of Legislative technique ${ }^{4}$.

Also, the lawyer scientist X.Haitov said that the result of the expert or group of experts with special knowledge and skills on the concept of the expert of the draft laws based on draft laws will be formalized in the form of a conclusion, identifying and eliminating the various shortcomings allowed in them, it has been described as an activity aimed at developing recommendations based on the evaluation of compliance of the draft laws with the legislative system, norms of international law, legislative techniques, the extent to which reforms are carried out in our country ${ }^{5}$.

In Particular, E.V.Razd'yakonova and E.D.Tretyakova divided the following types of expertise:

— depending on the subjects carrying out expert activities: State, Public, International;

— by the stage of complexity:

a )Essex (if a normative legal act or project relates to several areas of Legal Regulation);

b) specialized (if the draft normative legal act relates to some sphere of regulated social relations) ${ }^{6}$.

Engagement speaks to an evolving critical agenda in norm research, recognizing developing states as norm-makers rather than norm-takers and thereby counteracting a long-standing hierarchical depiction of norm promotion, development, and diffusion? ${ }^{7}$.

\section{Discussion}

The following scientific approaches of scientists on the concepts of "law-making", "rule-making", "lawmaking" and their differences can be shown in scientifictheoretical sources and research works.

In our opinion, based on the theory of law, it is expedient to describe the concepts of "lawmaking", 
"rulemaking" and "lawmaking" in terms of direct sources of law.

The activity aimed at creating, changing and repealing the rules of conduct, the implementation of which is mandatory, is "law-making", and only the development, amendment and repeal of normative legal acts should be understood as "norm-making". At the same time, it is appropriate to understand the concept of "lawmaking" only in the activities of the state legislature to create, amend and repeal laws governing social relations.

One of the manifestations of law-making is the issuance of individual, formal, authoritative and binding orders by the head of a particular organization or institution.

Based on the above, in terms of the creation, modification and repeal of universally binding rules of conduct, "lawmaking" is a broader category that encompasses the concepts of "rule-making" and "law-making.

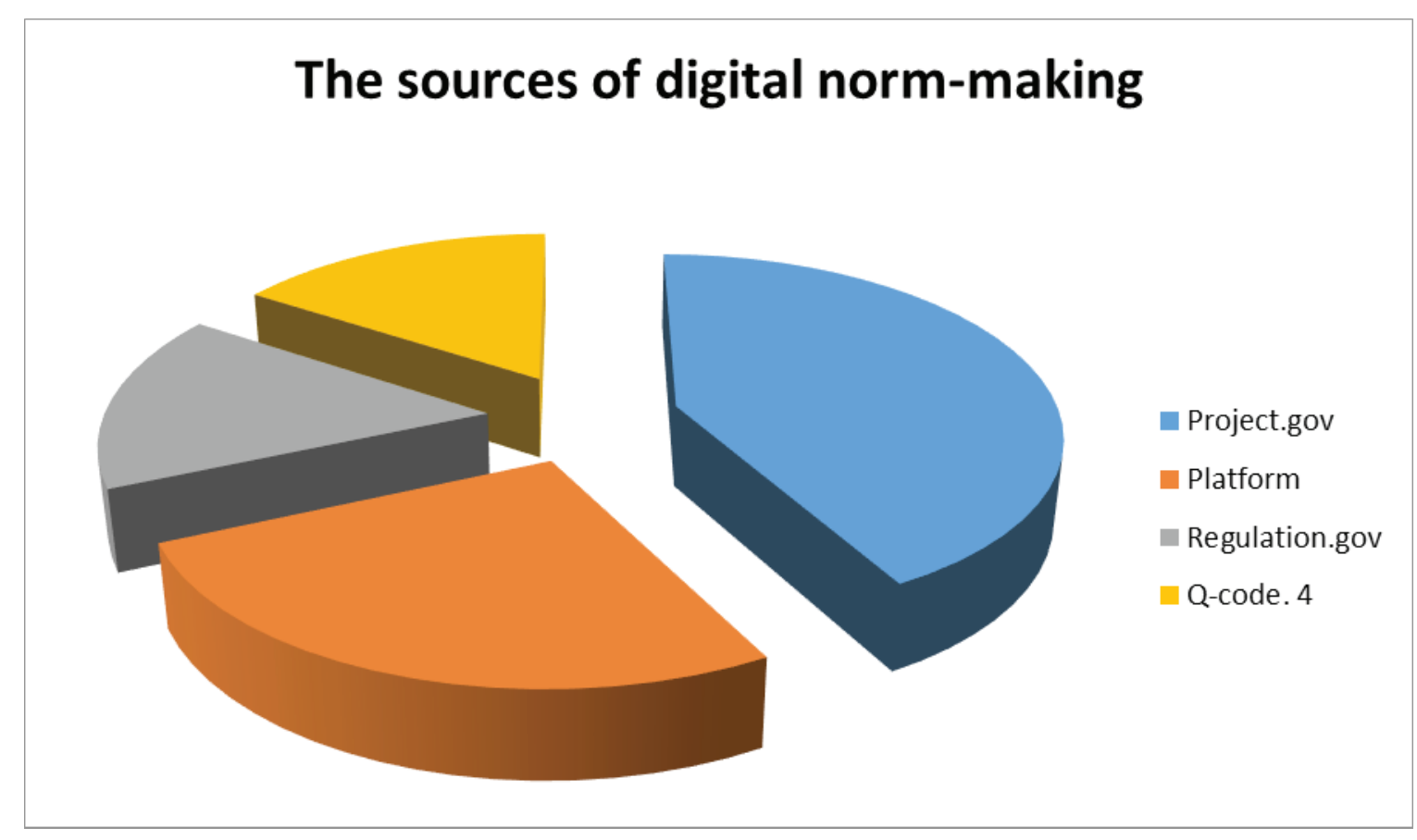

Figure 1.

Although there are theoretical approaches to the concept of norm-setting in the scientific literature, it can be shown that our national legislation has not developed a clear legal definition of the concept of "norm-creation initiative", "norm-creation activity", "subjects of norm-creation".

Due to the organizational and legal nature of the norm, it should be noted that this activity has the following characteristics:

First, that this activity covers the stages of preparation of the draft normative legal acts, which are one of the direct sources of law, their legal examination and coordination, discussion, adoption (issuance) with interested bodies and organizations;

Second, its adoption by a person or body authorized to adopt an official document aimed at establishing, amending or repealing legal norms as general mandatory state instructions;

Third, the existence of special procedures for the implementation of legislative activity, which is one of the main areas of this activity, in the manner prescribed by law; 
Fourth, the participation of the local population in these activities.

Normative activity is carried out by the principles of man, his rights and freedoms and legitimate interests, legality, democracy, transparency, agreement, logical consistency, expediency, scientific validity. It is expedient to define the concept of "norm-making technique", which applies to all types of normative legal acts, as a set of rules, methods and tools used in the development, legal and technical drafting, adoption of the draft normative legal acts.

The current state of the lawmaking sphere makes it possible to use digital technologies not as a means that can replace a person or significantly simplify his work, but as a means that accumulates the results of work and allows for operational interaction and information retrieval. At the present stage, the task of scientists and practitioners is to form the basic principles and directions of digitalization of law-making activity, to determine the limits and possibilities of its implementation in the lawmaking process ${ }^{8}$.

According to Mark D. Ryan and Gurchetan S. Grewa, digital technologies are applicable at the following stages of legislative activity:

- collecting public opinion through online forums;

- development of the draft laws using online mechanisms;

- Coordination of online consultations on draft laws;

- online voting on proposed bills;

- providing online access to current legislation and ensuring the interpretation of current legislation ${ }^{9}$.

According to V.Zikeev, the key issue of digitalization of the legislative process is the depth of implementation and the scope of digital technologies. It should be added that artificial intelligence is already capable of detecting defects in regulatory requirements, as well as ensuring the unification of legal terminology. The same can be said about some constructors of regulatory legal acts (by analogy with constructors of contracts), the creation of which will become a feasible task for developers of professional software. In this sense, the time for artificial intelligence in rulemaking has come.

State bodies should arm themselves with technological tools that allow them to reduce costs, free up human intellectual resources for solving non-routine tasks. However, this is a matter of serious managerial, in a sense, political will, because the delegation of even an insignificant amount of functions of the state apparatus to artificial intelligence can be associated with decisionmaking to optimize labor resources. Although the number of routine tasks is growing disproportionately with the growth in the number of management units, therefore, the priority in this regard is the reorientation of human resources to solve tasks that are not related to the performance of typical or routine work.

Technological solutions in the field of lawmaking will make it possible, among other things, to remove some procedural barriers (first of all, concerning numerous internal approvals at the stage of preparing documents). Thus, some experts believe that artificial intelligence can be delegated the functions of checking compliance with the procedure for submitting legislative initiative, selecting regulations and norms to be recognized as invalid as a result of the adoption of a new law, analyzing regulations for duplication of regulation at the stage of legislative initiative.

Neural networks could also be used to assess the regulatory impact of the planned draft law. In this regard, I am in solidarity with those who assign technology the function of a faithful and unpretentious helper. Despite the futuristic views of many representatives of the legal profession, I still do not see it possible to replace professional lawyers working in the state apparatus with robots. Experts note that the legislative initiative as a mechanism for putting into effect legislative activity contains elements of the will, the need for subjects of the right of a legislative initiative to respond to changing legal relations, socio-economic and other conditions, to suggest how such legal relations can change in the future. In the course of work on rule-making initiatives, analytical expertise is required, taking into account many social, economic, political, and historical factors. In every management decision, the "social context" is almost more important than the accuracy and clarity of 
regulatory prescriptions. Also, when making managerial, including legislative decisions, the issue of subjectivity comes to the fore. And in this sense, we are certainly far from the all-encompassing delegation of legislative functions to artificial intelligence. Therefore, undoubtedly digital products can significantly simplify the work of lawmakers and legislative bodies, as is done today by legal reference systems, but so far no more ${ }^{10}$.

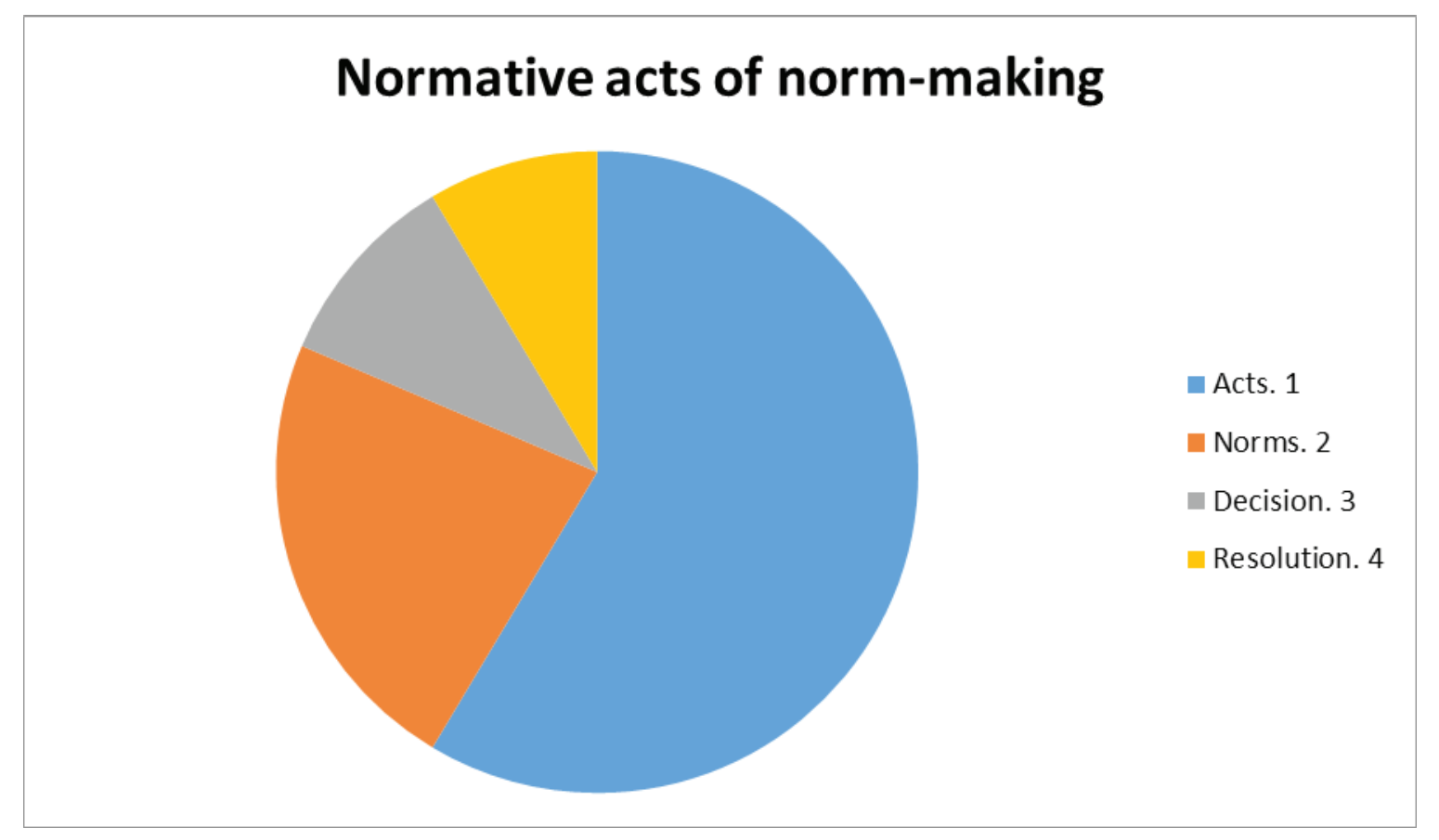

Figure 2.

In Uzbekistan, among the main events in the rulemaking activity was the launch on the Internet of the Unified Electronic System for the Development and Approval of the draft Normative Legal Acts. It should be noted that only in a few countries of the world, in particular Belarus, Kazakhstan, Korea, Russia, Singapore, Japan, and now in Uzbekistan, systems of this kind are functioning, allowing to carry out law-making activities in an electronic format. Automation of the procedure for approval (approval) of the draft regulatory legal acts made it possible to significantly optimize and simplify the rule-making process.

The electronic format of work allows you to quickly and conveniently coordinates drafts of normative legal acts. Due to the availability of the system via the Internet, non-compliance with the established deadlines for approval of the draft regulatory legal acts, red tape and bureaucracy in law-making activities are excluded. More than 200 different organizations are connected to the system, in particular, all government bodies, including khokimiyats. This year, the Unified Electronic
System for the Development and Approval of the draft Normative Legal Acts (project.gov.uz), as well as the System for Assessing the Impact of Legislative Acts (regulation.gov.uz), were transferred to the Ministry of Justice, which is the body authorized to implement the unified state legal policy, coordination and enhancement of the effectiveness of lawmaking. The Ministry of Justice carried out a legal examination in electronic format and endorsed about 1400 projects of normative legal acts ${ }^{11}$.

In our view, the institute of legal experiment and its structure, function, limits of its implementation and the legal status and guarantees of the participants of the experiment are not sufficiently developed. No specific criteria have been considered in which cases it is useful or necessary to carry out legal experiments. There is no normative legal document defining the procedure for organizing and conducting a legal experiment, recommendations and guidelines for their scientific organization, and regulating the objective examination of the results ${ }^{12}$. 


\section{Recommendation}

The impact of digital technologies on the law is directly manifested in lawmaking, which, under the influence of the new reality, may well change a number of its key parameters. The study of this impact and its main directions today is largely predictive in nature. Nevertheless, it seems possible to identify the main vectors of such an impact, to suggest possible solutions to emerging problems ${ }^{13}$.

In our opinion, in order to further develop the creative activity of the digital norm and expand its position in the field of legal technology, the following author's suggestions are given:

First, Mutual integration of Parliament, Presidential Administration, ministries and government into a single legislative platform. Through this platform, the bodies of the state engaged in norm-setting activities carry out the tasks of the drafting and reviewing, discussing and approving normative legal acts.

Second, complete abandonment of paper forms of normative legal acts and full transfer of documents to electronic form.

Third, the development of Q-codes of normativelegal documents. At the same time, it is important that Q-codes, which basically contain all the information about the product, also apply to the legal framework. In our opinion, the following positive results can be achieved through the introduction of Q-codes in the normative legal acts, in particular, it is expedient to publish the normative legal acts with the Q-code after approval, which includes the stages from drafting to signing and discussion. Include information on the acceptance or rejection of proposals and recommendations submitted by the population and government agencies. Therefore, it is expedient to develop a separate electronic database of the Q-code of the regulatory legal document on the website www.lex.uz (National Database of Legislation of the Republic of Uzbekistan). The electronic database of the Q-code contains information about the proposals that are the basis for the development of legislation and their authors, which in turn prevents the issuance of previously made and repeated proposals to improve the legislation and serves to provide quality and new proposals.

Fourth, the legislative initiative and the process of submission to the Legislative Chamber of the Parliament should be transferred to the online system.

These proposals will be taken into account during the pandemic and in other cases in the protection of the health and time of specialists working in law enforcement agencies.

\section{Conclusion}

In conclusion, it should be noted that, given the students of today, the activity of norm-making is aimed at breaking the law, so this activity should be further improved. At the same time, the digitization of normative activity and the use of digital normative activity during the "Pandemic COVID-19" directly contribute to the protection of human health.

Conflict of Interest: None to declare

\section{Source of Funding: Self}

Ethical Approval: No ethical approval is needed.

\section{References}

1. ru.wikipedia.org

2. Islamav ZM. Problemi teorii gosudarstva I prava sovremennosti. Uchebnik. - T.: TGYuI, 2006. p. 10 .

3. Najimov MK. The lawmaking. The textbook. Tashkent: TDYOU, 2018. p. 77.

4. Skorka EV. Nekatorie Vaprosi integrasii ekspertnogo znaniya $\mathrm{V}$ zakonodatelnuyu deyatelnast // Predstavitelnaya vlast - XXI vek: zakonodatelstva, kommentarii, problem, 2002. № 2-3. p. 46.

5. Khayitav XS. Improvement of the organizational and legal basis of expert examination in the creativity of the law. Doctor of Legal Sciences (DSc) the dis. authorship. T.: 2018. p. 14.

6. Razd'yakonova EV., Tretyakova ED. Pravovaya ekspertiza normativnix pravovix aktov: Uchebnoe posobie / SIU-branch Ranhigs. - Novosibirsk: izdvo Sibags.-2014. p. 54.

7. Bode I. Norm-making and the Global South: 
Attempts to Regulate Lethal Autonomous Weapons Systems. Global Policy, Volume 10, Issue 3, 1 September 2019, p. 359-364, (www.scopus.com)

8. Arnautova A. Digitalization of law-making activities. Electronic scientific journal "Century of quality". no.2 (2019).

9. Mark D.R. and Gurchetan S.G. Making laws in a digital age, 2014.

10. https://zakon.ru/blog/2020/03/02/ zakonotvorchestvo_i_cifra_longrid_na_temu

11. https://www.minjust.uz/ru/press-center/ news/98818/

12. Rakhmatullayevich KS. Legal experiment: ITS concept, classification and role in improving normmaking, Volume 7, Issue 2, September 2020, pages 701-708 (www.scopus.com)

13. The digitalization of law-making: the search for new solutions : monograph / Pashentsev DA, Zaloilo MV, Ivanyuk OA, Golovina AA; ed. by doctor of law, professor Pashentsev DA. Moscow: The Institute of Legislation and Comparative Law under the Government of the Russian Federation: INFRA-M, 2019. p. 10. 